\title{
EIחतA
}

Revista Eletrônica de Estudos Integrados em Discurso e Argumentação

\section{A INVENÇÃO DA RETÓRICA OU A TRANSGRESSÃO DOS LIMITES DO MUNDO FECHADO'}

\section{Loïc Nicolas ${ }^{\text {ii }}$}

Resumo: Este artigo objetiva estudar a arte retórica e sua invenção na Grécia Antiga em termos de transgressão. Minha análise enfoca a figura do inventor desta arte, ou seja, o sofista. De Platão aos dias de hoje, ele é o oponente do filósofo e o amigo da doxa - o senso comum. O sofista representa, ainda hoje, um problema filosófico e, ademais, um problema de significado. Ele é, acima de tudo, um corruptor de mentes, um fornecedor de argumentos inadequados e um artesão de mentiras: uma ameaça para a sociedade. Contudo, nós precisamos tentar ir além e considerar sua abordagem retórica. $O$ sofista, de forma mais profunda, é visto como um encrenqueiro, porque ele subverte as evidências e as certezas de um mundo fechado. Acerca dos deuses, da sociedade e das leis, ele sempre faz uma pergunta a mais, abrindo o mundo e propondo a transgressão de seus limites e fronteiras. Ele convida os cidadãos, acerca de qualquer tópico, para uma jornada orientada a argumentos possíveis e provas retóricas. Nesse sentido, o objetivo deste estudo é mostrar que não são exatamente as ideias dos sofistas que são problemáticas, mas a jornada que ele viabiliza ao ensinar as ferramentas da argumentação.

Palavras-chave: Sofista. Retórica. Argumentação. Pensamento livre.

\begin{abstract}
This paper aims to study the art of rhetoric, and its invention in ancient Greece, in terms of transgression. My analysis focuses on the figure of the inventor of this art, that is to say, the sophist. From Plato to nowadays, he is the opponent of the philosopher and the friend of the doxa - the common sense. The sophist poses, still today, a philosophical problem, and, moreover, a problem of meaning. He is, above all, the corrupter of minds, a purveyor of bad arguments, and a craftsman of lies: a threat for the society. But we must try to go further, and consider his rhetorical approach. The sophist, more deeply, is seen as a troublemaker because he upsets the evidences and certainties of the closed world. On the gods, on the society, on laws, he asks always one more question, opens the world and proposes to transgress its limits and borders. For any topic, he calls the citizens to a journey towards possible arguments and rhetorical proofs. Thus, the goal of this study is to show that it is not so much the ideas of the sophist which are problematic, but the journey that he makes possible by teaching the tools of argumentation.
\end{abstract}

Keywords: Sophist. Rhetoric. Argumentation. Free thinking.

' Tradução do original em francês: NICOLAS, Loïc. I'invention de la rhétorique ou la transgression des limites du monde clos. In: HASTINGS, Michel; NICOLAS, Loïc; PASSARD, Cédric (Org.). Paradoxes de la transgression. Paris: CNRS Éditions, 2012. p. 139-154.

ii Doutor em Línguas e Letras pela Université Libre de Bruxelles (ULB), Bélgica. Pesquisador na mesma instituição e membro do Groupe de recherche en Rhétorique et en Argumentation Linguistique (GRAL/ULB). E-mail: Loic.Nicolas@ulb.ac.be. 
EID\&A - Revista Eletrônica de Estudos Integrados em Discurso e Argumentação, Ilhéus, n. 11, jan/jun.2016.

\section{Introdução}

O objetivo do presente artigo é conduzir uma discussão sobre as potencialidades libertadoras do ato transgressivo. $O$ ato pelo qual o homem dá a si mesmo os modos de pensar e de julgar, de penetrar o mundo fora das regras estabelecidas, de enfrentar a incerteza própria de suas questões como homem. Nesse sentido, transgredir consiste em se emancipar desse estado de tutela que o impede de caminhar e de pensar mais adiante, ou seja, ir além dos limites do mundo fechado ${ }^{1}$. A finalidade dessa exposição é, portanto, refletir, de modo contíguo, sobre o exercício da crítica, da transgressão e da aprendizagem da autonomia. Nesse sentido, meu estudo se interessa pela ultrapassagem de um limite, de uma fronteira. Em suma, refere-se ao patamar - supostamente imutável - através do qual finalmente se abre para o desconhecido de um estado libertador no qual a coragem (de dizer o mundo, de fazê-lo significar) e a invenção (como capacidade de imaginação, mas também de antecipação) podem se lançar.

O texto que vamos ler trata da ultrapassagem de uma barreira, ou seja, sobre uma viagem do pensamento à procura de suas próprias leis, em busca de uma medida prática dos seres e das coisas. Esta viagem indica a denúncia, ou até mesmo a renúncia à ordem, supostamente necessária, que até então sustentava o mundo. Há, no ato de transgressão pensado, uma desobstrução do sentido, uma ameaça, uma aceitação do precário. Pensemos, nesse momento, nos marinheiros de outros tempos que escolheram navegar mais longe e experimentar, apesar dos pesares, as extremidades ilusórias da terra plana. A esse respeito, proporei aqui uma reflexão à margem da maioria das contribuições da obra coletiva Paradoxes de la transgression (HASTINGS; NICOLAS; PASSARD, 2012); à margem, mas também em diálogo com elas. Isso se dá na medida em que a transgressão aqui abordada não se refere a nenhum crime nem delito: nada de sangue, nada de sexo, nada de ataque ao sagrado, nada de desvio social ${ }^{2}$. No entanto, esta transgressão não se torna menos

\footnotetext{
${ }^{1}$ Eu penso aqui especialmente em Popper (1979 [1945]).

${ }^{2}$ Vide MAFFESOLI \& BRUSTON (1979), JENKS (2003), CHARTIER (2010). Chris Jenks inicia sua obra evocando os atentados de 11 de setembro de 2001. O choque que eles representaram, o qual se transformou rapidamente em medo, em horror, tornando tangível o sentimento partilhado de uma fratura, nascida de uma transgressão absoluta. Fratura que, nesse momento, se fez mobilizadora, portadora da consolidação e da afirmação coletiva. O autor destaca então (p. 2-3): "To transgressis to go beyond the bounds or limits set by a commandment or law or convention, it is to violate or infringe. But to transgressis also more than this, it is to announce and even laudate the commandment, the law or the convention. [...]. An analysis of the concept "transgression" will take us a long a series of continua, both vertical and horizontal, such as sacred-profane; good-evil; normal-pathological; sanemad; purity-danger; high-low; centre-periphery and soon. [...]. Our
} 
EID\&A - Revista Eletrônica de Estudos Integrados em Discurso e Argumentação, Ilhéus, n. 11, jan/jun.2016.

radical do que as outras. Ela anula os limites existentes, revelando que podemos ir, andar, navegar, pensar mais adiante e, uma vez partindo, arriscar os limites da exploração da terra desconhecida. O transgressor que vou apresentar é, sem dúvida, um mostro, um objeto de fascinação e de fantasias. é esta a razão pela qual foi perseguido por alguns, foi suspeito, denunciado em seu tempo como corruptor (da juventude, da moral pública) e como artesão da desordem. Contudo, sua monstruosidade provém, antes de mais nada, do fato de que ousa abrir as prisões do espírito. Com efeito, seu objetivo é engajar aqueles que vêm ao seu encalço nas vias da argumentação contraditória, da crítica e da dúvida. Coveiro das evidências religiosas, políticas e filosóficas do mundo fechado, o sofista de ontem e de hoje encarna e convida para a transgressão. Ele desempenha o papel de monstro viajante, isto é, de viajante livre, totalmente livre... Ele não tem medo de sujar as mãos com o verossímil (esta verdade retórica), com as opiniões, com os percalços do sentido, com a técnica. Ele não hesita em traçar um caminho em meio à incerteza; em pensar a palavra como ação, bem como em termos de eficáciả. É a esta suposta figura manipuladora - tão depreciada ainda em nossos dias que eu dedicarei os desenvolvimentos a seguir.

Para compreender bem a metáfora da viagem que serve de fio condutor para esta introdução, uma passagem por Kant me parece proveitosa. No início de sua célebre dissertação sobre o lluminismo, ele se interroga sobre o estado de inferioridade próprio aos homens que, por comodidade ou por covardia, geralmente, se deixam conduzir por outros - seus tutores. Estes últimos têm por tarefa a obrigação de cuidar desses homens, advertindo-os sobre os imensos perigos de uma circulação autônoma: "Inicialmente, após ter tornado estúpido todo o rebanho doméstico e cuidado para que estas tranquilas criaturas não pudessem ousar dar o menor passo fora do cercado no qual

analysis of transgression will take us through a variety of empirical contexts such as crime, sexuality, ritual, carnival, art, culture and madness". Jenks (em um percurso que cruza os campos da sociologia, da psicologia, da filosofia, da literatura, da arte, da criminologia, etc.) busca mostrar que a transgressão está no centro das sociedades contemporâneas, tomada por inúmeros limites físicos, estéticos, sexuais, nacionais, legais e morais.

3 Em todos os aspectos, o sofista ultrapassa os limites e mistura os gêneros: ele se dedica a fazer da filosofia "um discurso como o outro" (ele não respeita, portanto, a separação), conduzindo-a dentro das águas turvas povoadas de ideias ignóbeis - a infração é clara. Como escreve G. Benrekassa: "O sofista cruza os limites: como o turannos transgride os limites da cidade, ou se mantém tanto o cidadão como o Basileus. [...]. [Para o filósofo, o] sofista é o mais próximo de um pervertido, um pervertido que perturba, que não se contenta em se servir da linguagem para seduzir [...], mas para desorientar "realmente", o exercício legitima o pensamento" (BENREKASSA, 2004, p. 19-44). Nós teremos a oportunidade de retornar este aspecto do problema, segundo o qual o sofista seduz, confunde, faz perder o fio do pensamento correto e do bom senso. 
EID\&A - Revista Eletrônica de Estudos Integrados em Discurso e Argumentação, Ilhéus, n. 11, jan/jun.2016.

estão encerrados, [seus tutores] mostram-lhes, em seguida, o perigo que enfrentariam se tentassem caminhar sozinhos. Ora, este perigo, na verdade, não é tão grande, uma vez que algumas quedas acabariam por lhes ensinar a andar [...]" (KANT, 1985 [1784]). Kant chama a atenção para o perigo que representa a queda quando se trata de se mover sem ajuda, ou seja, pensar por si mesmo - seja para escolher e decidir aquilo que é bom ou justo, seja para fazer uma escolha, etc. Contudo, é necessário mencionar um outro perigo, ainda maior que o primeiro, que ameaça tanto o aprender a caminhar como o julgamento: saber se engajar fora do cercado, poder transgredir seus limites por inconsciência ou por curiosidade... sob o risco de se afastar e de ter encontros desagradáveis. Além disso, o risco em questão não constituiria, ao mesmo tempo, uma chance para exercer sua liberdade de pensamento colocando-a tanto à prova do mundo, quanto à prova dos outros? Compreendamos: se os tutores dos quais fala Kant temem tanto a autonomia de seu rebanho doméstico, é sem dúvida alguma devido ao medo de vê-lo avançar sozinho, contestando a sua tutela. Mas também porque, sendo autônomo, ele poderia querer ultrapassar o limite do pensável e percorrer o mundo (do espírito e da razão) sem guia nem pastor, estando aí compreendidas as consequências imprevisíveis que isso pode ter. $O$ perigo é grande para a perenidade da ordem do mundo: suas normas, suas regras, seus valores, suas fronteiras, pensadas ou não, como é também para aqueles se empenham em fazer respeitar esta ordem no estado.

Minha análise, a partir de agora, irá se realizar em dois momentos: após ter recordado as condições de invenção da retórica e o lugar dos sofistas neste campo (1), tentarei explorar a figura do viajante livre que, pela argumentação, trabalha o sentido para torná-lo precário (2).

\section{Os sofistas e a técnica retórica}

Há, de imediato, algo de transgressivo em querer apresentar o sofista, sobretudo os sofistas já que eles jamais constituíram uma escola no sentido próprio, apesar do interesse comum pela linguagem e o projeto de ensinar a virtude (aretè) política. Pensamos os sofistas como libertadores do pensamento, educadores ligados à emancipação da mente humana, em lugar de uma razão até então restritiva. Vendo-os, digamos, como os partidários de uma Aufklärung inaugural, partidários dos humanistas, como sendo os 
EID\&A - Revista Eletrônica de Estudos Integrados em Discurso e Argumentação, Ilhéus, n. 11, jan/jun.2016.

primeiros a se esforçarem para promover um "ideal cultural4" (cf. JAEGER, 2007 [1933-1947], p. 349), trabalhando para liberar o homem da influência das forças naturais (cósmicas) e da religião. Na esteira dos trabalhos de Jaeger (2007 [1933-1947]), Dupréel (1948), Marrou (1965 [1948]), Gusdorfe (1967) e, mais recentemente, Cassin $(1986,1995)$, minha abordagem coloca-se contra a corrente de nossa tradição intelectual - herdeira de Platão, para quem os sofistas não eram nada mais do que mentirosos e falsários, línguas loucas. Apreciador de metáforas culinárias, o Sócrates dos Diálogos retrata o seu outro negativo (o sofista, pretenso sábio, suposto guia), tanto como "uma espécie de comerciante e de traficante de mercadorias das quais a alma se alimenta" (PLATON, 2002 [1967], p. 45, Protágoras, 313c), quanto como um cozinheiro de opereta que ignora totalmente os "alimentos mais saudáveis para o corpo", e cuja "prática visa ao agradável, negligenciando o bem" (PLATON, 2002 [1967], p. 193, Gorgias, 465b).

Em outras palavras, enquanto o filósofo cuida da alma, o sofista dedicase à confortar suas más inclinações, fornecendo, à vontade, doces e purês. Falsificador, ele inverte, segundo seus opositores, a realidade e a aparência, o mundo real e a ficção. Ele presta atenção somente nas "belas vozes, [nas] belas cores e [nas] outras coisas semelhantes", desprezando tudo aquilo "que [é] o objeto das ciências" e submetido à verdade (PLATON, 1950, p. 206, La République, $\mathrm{V}, 480 \mathrm{a})$. Esse discurso é bem conhecido. Neste momento, o que me importa é questionar as razões profundas e refletir para além da doxa filosófica. Para tal finalidade, farei um retorno ao momento de nascimento do projeto sofístico. Um projeto que tinha então a intenção de fazer do discurso o suporte da liberdade política, oferecendo um método (a retórica) suficientemente flexível para que os homens pudessem se orientar na contingência dos futuros e, por conseguinte, aprender sua profissão de homens.

Retomemos o termo "sofista", sofistas5 (que encontramos nas acepções mais variadas em Ésquilo, Eurípedes, Hipócrates, Aristófanes, por exemplo)

\footnotetext{
4 Consultaremos mais amplamente as páginas 333-381. Falar dos "humanistas" pode surpreender, Jaeger, a quem me refiro e defende o emprego do termo (Ib.): “Nós não nos servimos desta palavra humanismo como vago equivalente histórico de um fenômeno mais antigo; nós utilizamos deliberadamente e lhe dando seu sentido próprio, para qualificar o ideal cultural que, após uma longa incubação no espírito da Grécia, se revelou enfim no ensino dos sofistas".

5 Indiretamente derivado de sophós (sábio) e, diretamente do verbo sophízesthai (imaginar, inventar; fazer o exercício de uma arte seja ela qual for, fazer disso profissão), sofistas qualifica todo homem que desenvolveu uma avaliação/experiência, uma competência especial em relação a uma técnica determinada - que esta seja, por exemplo, a medicina, a navegação, a astronomia, a
} 
EID\&A - Revista Eletrônica de Estudos Integrados em Discurso e Argumentação, Ilhéus, n. 11, jan/jun.2016.

que designa, originalmente, qualquer artesão, inventor ou mestre em um domínio no qual se pode exercer uma determinada technè. É um sofista o homem - "conhecedor de algo" - que fez da técnica ou da arte o lugar de seu domínio e que, em consequência, tornou-se apto para assegurar a sua transmissão, para instruir os aprendizes. Isso somente é possível num contexto social e político no qual as técnicas foram laicizadas, isto é, separadas das forças religiosas. Este é o contexto no qual o sucesso técnico assumiu sua autonomia face ao feito mágico (aquele dos magos e dos curandeiros de outrora). Experiência, habilidade, riqueza criativa, mas também fracassos, erros, derrotas, dúvidas ganham sentido numa visão instrumental de apropriação e de adaptação a um mundo tornado acessível. O homem começa "por seus esforços árduos [... à] impor sua vontade aos elementos" (JAEGER, 2007 [1933-1947], p. 362); ele começa a agir diretamente sobre a natureza (a physis) com suas habilidades de homem, sem a mediação dos deuses, sem filtros, sem magias. $O$ aprendiz (arquiteto, médico, navegador, curtumeiro, etc.), de quem o sofista é encarregado de ensinar, pode aprender as sutilezas da profissão" para tornar-se, por sua vez, um mestre na matéria, para travar, como escreve Vernant, seu próprio "combate da technè contra a physis" (VERNANT, 1996 [1965], p. 309)

Com a entrada na democracia no século $V$ da era pré-cristã, o discurso também pareceu, ao menos para alguns, poder ser objeto de uma abordagem técnica, isto é, passar sofisticamente por um reflexão. Entretanto, acima de todo, interessava fazer do discurso o lugar de aprendizagem especializada, atribuir-Ihe competências particulares, mostrar que a atividade de falar praticada de forma aparentemente tão "natural" não seria, por si só, suficiente - muito pelo contrário. No final das contas, esta abordagem que introduz na palavra as ferramentas para compor, lapidar e modelar os discursos foi julgada "sem natureza", contra-natureza, artificial. Todavia, é a própria existência de tal exercício intelectual, de um tal procedimento, que revelou o caráter convencional da linguagem - que convida a opor physis (natureza) e nomos (convenção, lei). Esta oposição que envolve a reflexão técnica é exemplar do movimento de laicização. $O$ homem pode se fazer "artesão das palavras" (independentemente das coisas); sua competência e sua eloquência deixam de ser vistas como dons de Deus ou como resultado de uma ação mágica. Ora, se o homem pode se fazer artesão das palavras, é 
EID\&A - Revista Eletrônica de Estudos Integrados em Discurso e Argumentação, Ilhéus, n. 11, jan/jun.2016.

porque a linguagem tornou-se, igualmente, uma instituição humana habitada pela convenção e, mais ainda, o lugar privilegiado da elaboração da convenção. A reflexão, de agora em diante, toma como ponto de apoio o fato de que existe, quanto à invenção dos discursos, uma técnica e um saber-fazer, cuja aquisição e domínio não se originariam da pura e simples aprendizagem da língua. Por consequência, trata-se de uma prática autônoma cuja natureza e o funcionamento necessitam das competências e de uma transmissão específicas. Os sofistas comprometem-se assim a levar em consideração as normas sociais, os usos e as competências psicológicas que habitam a língua para além de suas regras (gramáticas, sintáticas) e de suas palavras.

$\mathrm{Na}$ realidade, este interesse pelo discurso (e suas técnicas) está intimamente ligado à animação e à evolução democrática que marcou a maior parte das cidades gregas - especialmente Atenas - depois da crise da tirania no século VI antes da nossa era. De fato, a democracia (direta) que progressivamente se instala tem por principal característica, ao lado de uma igualdade diante da lei (isonomie), ser isegórica: ela concede uma igualdade de acesso à fala para todos os cidadãos que a solicitam. Cada homem é livre e responsável e vê-se dotado, não somente de um mesmo "direito à fala, mas também de um dever de fazer uso da palavra" (COULOUBARITSIS, 1994), de praticá-la, de apoderar-se dela. Contudo, a educação grega tradicional (sobretudo artística e esportiva) não permitia, no seu estado, à época, relevar os desafios da evolução democrática. Ou seja: preparar os futuros cidadãos (os futuros homens livres) para as novas instituições, bem como para as carreiras políticas que viessem a se apresentar e às quais eles poderiam aspirar. Não existia, até então, nenhum método determinado - para além da velha formação aristocrática - para guiar os homens sobre o difícil caminho da cidadania. De fato, a existência destas faltas abriu uma brecha, alimentou uma demanda, engajou reflexões, suscitou vocações professorais. Em consequência disso, como destaca Jaeger, "é fácil compreender o motivo do aparecimento de uma classe de educadores que, de acordo com o que declararam publicamente, destacaram-se em ensinar" (JAEGER, 2007 [19331947], p. 338) a eloquência política, em outras palavras, a arte (technè) e a aretè ao cidadão.

Além disso, como remediar as insuficiências do sistema a não ser fornecendo aos espíritos da época este equipamento intelectual e prático que, cruelmente, fazia-Ihes tanta falta? Um equipamento (de saber-fazer, de 
EID\&A - Revista Eletrônica de Estudos Integrados em Discurso e Argumentação, Ilhéus, n. 11, jan/jun.2016.

conhecimentos, de competências) que pudesse ajudar cada um a tomar posse da palavra nas questões da cidade: para se defender, para acusar, para julgar, para persuadir, para governar. A palavra pública foi erigida como necessidade política e social através de gerações de jovens que viam nela, certamente, um meio de ter êxito, mas também uma forma de serem livres: livres para dizer e se engajar no dizer. Desde então, essa palavra pode ser o objeto de uma investigação própria sobre as condições de sua eficácia, bem como de um trabalho de observação sobre seu poder e suas técnicas. Técnicas estas que necessitavam de identificar, catalogar, testar, aperfeiçoar a fim de que se tornasse possível - segundo os termos empregados por Hippocrate em Protágoras - "tornar os homens hábeis para falar" (PLATON, 2002 [1967], p. 45, Protagoras, 312d). Sem dúvida, a tecnicização da invenção discursiva testemunha uma evolução radical. Ela permitiu abordar o discurso como o modelo de todas as outras criações humanas: aquelas do artesão, do cientista ou de qualquer inventor. A linguagem é considerada, então, como uma produção e como um lugar de produção. Neste sentido, os sofistas são os representantes exemplares de seu tempo; eles somente revelaram, pelo projeto educativo "a verdadeira natureza do espírito helênico e a faculdade que ele tinha de se unir ao universal, ao conjunto da vida" (JAEGER, 2007 [1933-1947], p. 362).

Contudo, a abordagem que eles iniciam parte de um triplo postulado, simples e perturbador ao mesmo tempo - fortemente transgressivo - que seus contemporâneos não estavam, de forma alguma, prontos para assumir tais implicações: (1) não é mais fácil, nem mais evidente, fazer-se compreender no espaço do discurso para defender uma causa e ganhá-la do que conduzir um barco e aportá-lo ou reparar uma fratura; (2) esta ausência de facilidade e de evidência pode ser abordada e depois absorvida através de uma técnica para se chegar a (3) tornar-se mestre daquilo que pertence somente ao ser social, a saber: o sentido das coisas e como elas são irredutivelmente humanas. Nesta perspectiva, o fato de que o objeto a ser produzido seja composto de palavras, de frases e passe pelos canais da linguagem comum não muda nada. Sem técnica, o orador (à semelhança do navegador que improvisa ou do médico por um dia) é igualmente forçado a confiar quase que totalmente no acaso ou na boa sorte, tornando-se obrigado a se entregar aos poderes do sobrenatural. Certamente, a palavras estão disponíveis para serem faladas, elas têm sentido, mas o método capaz de dar ao discurso esta eficácia que ele não possui naturalmente, não lhe é acessível. Eficácia esta que está sempre por construir e, 
EID\&A - Revista Eletrônica de Estudos Integrados em Discurso e Argumentação, Ilhéus, n. 11, jan/jun.2016.

sobretudo, por conquistar. É preciso tornar-se mestre para se chegar aos fins buscados e limitar, na medida do possível, os riscos de fracasso. É assim que se abre uma "nova era de racionalidade" (DANBLON, 2004, p. 13).

De fato, o objetivo específico de uma técnica consiste em diminuir o lugar do acaso no empreendimento de criação. Ou seja, a técnica fornece ao técnico os procedimentos empíricos que, até o presente, constituíram suas provas. Ela veicula uma sequência de precedentes e, finalmente, de "habilidades" e de "destrezas", processos sobre os quais podemos dizer que funcionam, mas sem necessariamente sabermos o porquê. Por conseguinte, a ênfase é inicialmente colocada na eficácia de uma situação. Compreendamos aqui que o domínio dos próprios recursos para a eficácia buscada por aquele que toma a palavra necessita de uma aprendizagem, de um trabalho sobre $o$ que é eficaz, aceitável, persuasivo, e sobre o que não é. Além disso, a técnica do discurso, seu domínio, surgiu como tendo um poder sobre o mundo que se revelou maior que qualquer técnica tradicional; um poder agente. Ou, dito de outra forma, a técnica comportaria recursos práticos que se supõe fornecer a oportunidade demiúrgica de uma ordenação inigualável e, por consequência, inquietante do mundo. Como se, por esta "mecânica" que fornece uma espécie de alavanca para o discurso (VERNANT, 1996 [1965], p. 311), o homem se tornasse capaz de produzir, por si mesmo, o mundo contra sua própria natureza e sua própria ordem, tornasse capaz de fazê-lo seguindo sua vontade, invertendo, como Prometeu ${ }^{6}$, a ordem dos poderes existentes. Num campo de espírito aberto à técnica, tanto a fraqueza como a força não são estados permanentes inscritos na natureza das coisas. Ao contrário, são recursos dinâmicos sobre os quais o discurso pode se apoiar, tanto num sentido como no outro. Recursos estes que o orador deve, por força de tentativas e erros, aprender a controlar. Assim sendo, em certas circunstâncias, um "pequeno" argumento poder ser muito mais estimulador (mais flexível e mais resistente) que outro "maior" e considerado mais "forte", incapaz de se adaptar ao contexto e ao auditório.

A transgressão está aqui: se o homem é a medida das coisas humanas7, Ihe é possível - em relação a estas coisas, não em relação ao mundo em geral

\footnotetext{
${ }^{6}$ Bárbara Cassin (1995) destaca que "O homem não é [...] somente moldado ou dotado por Prometeu, ele é prometeico ele próprio na medida em que ele modela seus discursos e os 'ficciona"” (Ib., p. 479).

7 Eu faço referência aqui à posição de Protágoras, referido por Sócrates do Teeteto (166d), para contestá-la: "Pois, eu afirmo que a Verdade é tal qual eu a escrevi: medida é cada um de nós (cada homem) e daquele que é e daquele que não é".
} 
EID\&A - Revista Eletrônica de Estudos Integrados em Discurso e Argumentação, Ilhéus, n. 11, jan/jun.2016.

- "fazer o mais fraco dos dois argumentos tornar-se o mais forte"; fazer com que o menor domine o maior: que Davi possa vencer Golias. Aqui, o combate da technè contra a physis toma uma amplitude sem precedentes: é no domínio da palavra que se joga, integralmente, a liberdade humana, sua confrontação com o mundo, com a sua ordem e com a "ambiguidade" indissolúvel que a caracteriza. Esta liberdade oferecida pela técnica representa incontestavelmente um perigo face aos limites de um mundo até então considerado fechado.

\section{Abrir o mundo e percorrê-lo}

O sofista impede que se pense em círculos. Ele convida a percorrer o mundo dos possíveis - onde tudo é para se questionar - pela ação do discurso eficaz e pelo trabalho incessante da argumentação. Ele apresenta meios, uma bagagem, um método para empreender esta viagem intelectual que toma forma sob os efeitos do discurso elaborado com e contra o outro. Uma viagem originada e, mais ainda, focada na busca de provas discursivas, de razões, de justificações, que sempre revelam seu valor prático em sua fragilidade. Ela testemunha, assim, a abertura dos enunciados para uma refutação cuja potencialidade não pode jamais ser excluída e que, por força da incerteza, está sempre por vir. Concretamente, a via argumentativa é semelhante a essa precariedade incessante. Lugar de passagem, ela deixa cada um livre (portanto, responsável) para convocar as técnicas do discurso, quaisquer que sejam as razões: com as consequências, boas ou más e amplamente imprevisíveis que se possa ter. As técnicas estão sempre presentes, disponíveis, sem tomar partido: que se trate de defender uma causa ou de denunciá-la; de apoiar o a favor ou de defender o contra; de tornar aceitáveis os argumentos contraditórios de posições totalmente opostas. A argumentação retórica permite emancipar o sentido diante de uma fala sem flexibilidade e sem fragilidade que teria, por ambição, uma fixação duradoura, ocasionando a proibição da crítica. Esta libertação efetua-se, assim, reconhecendo no homem (e somente nele) sua qualidade de "medida" (isto é, de "critério") do sentido das coisas humanas. Assim, o fato de reconhecer-lhe esta qualidade implica em aceitar, ao mesmo tempo, a incerteza positiva de seus discursos e a precariedade de suas palavras. Primeiramente, o sentido vale porque podemos confrontá-lo, isto é, determiná-lo, refletir sobre sua

${ }^{8}$ Aristóteles (Retórica, Il,1402a, 24) atribui esta prática à Protágoras. 
EID\&A - Revista Eletrônica de Estudos Integrados em Discurso e Argumentação, Ilhéus, n. 11, jan/jun.2016.

abrangência. Igualmente, é seu caráter revogável que permite o percurso em direção ao melhor e, assim, à possibilidade do progresso.

Todavia, se o sentido é precário e instável, de modo algum, isso implica nem a ausência total de sentido, nem o arbitrário da escolha. De fato, o sentido em questão não pertence propriamente nem às "coisas" nem ao mundo que ele compreende, visto que é, antes de mais nada, social. Para dizer de forma clara, o sentido adquire sentido apenas pelo efeito dos argumentos e dos discursos que, temporariamente, visam à aceitação sem restrição de uma possibilidade num dado auditório. Este, por sua vez, permanece sempre livre para dar seu consentimento ou para recusá-lo; livre para se deixar persuadir pelas teses ali apresentadas. O homem retórico que os sofistas têm em vista é, por definição, privado da segurança reconfortante característica do mundo natural ou divino da necessidade. Um mundo no qual as coisas têm um sentido sem a menor necessidade de ser buscado, argumentado, justificado, discutido, corrigido, substituído. Entregue a si próprio, alimentado pela dúvida, o homem retórico é forçado a correr riscos e dar provas de audácia, mas também da prudência9 (o que os Gregos chamavam phronèsis) para encontrar a via de uma liberdade razoável, para colocar suas escolhas e garantir a sua aceitação, apesar de tudo. Mas este desconforto é o preço a pagar por dotar, de um lado, a persuasão e, de outro, a adesão, de um valor eminente. A adesão nunca é adquirida, permanece sempre por conquistar; ela é um horizonte de expectativa do qual convém reconhecer e aceitar a fragilidade.

Assim, compreendemos porque a metáfora do "mau viajante" ou do "mau guia" continua bastante disseminada pela crítica, desde a antiguidade, para caracterizar o sofista por oposição ao filósofo. Através desta metáfora se traduz a inquietude face ao percurso e à liberdade revelados sob os efeitos do verbo técnico. O sofista, no imaginário coletivo, inclina-se pela arriscada via do acaso, da imprudência, via esta que ele mesmo dispõe e desvela para a infelicidade de todos. Acusado de não conhecer o mapa, ou talvez cegado por ele, diz-se que não pode lê-lo. Sua progressão incerta, tateante, torna sua incompetência indubitável. Ele ignora as fronteiras, despreza os limites, anda, se perde, retorna ao caminho, prossegue sua rota sem saber muito para onde ela vai levá-lo. Cada erro, cada problema, torna-se, para ele, um pretexto para prolongar, ainda mais, sua busca interminável. $\mathrm{O}$ fracasso não condena sua

9 Consultaremos com proveito o trabalho de Goyet (2009). Além disso, o artigo de Emmanuelle Danblon incluído no presente volume propõe uma leitura extremamente fecunda da prudência nos Gregos e esclarece as ideias que eu desenvolvo nestas páginas. 
EID\&A - Revista Eletrônica de Estudos Integrados em Discurso e Argumentação, Ilhéus, n. 11, jan/jun.2016.

progressão, pelo contrário, ele o alimenta. Desse modo, o sofista, antifilósofo por excelência, guia incapaz e impostor, se encontra forçado a andar incansavelmente, como em exílio perpétuo tanto num mundo terrestre, quanto no mundo das ideias. Ignorando ou recusando os limites do referido mundo, ele está em uma perpétua transgressão. Ele permanece incapaz de parar no tempo, incapaz de distinguir o momento em que a luz da verdade começa a enfraquecer.

Por outro lado, o afastamento espacial, físico, torna-se sinal de uma dispersão mental, de uma separação, de um desvio, de uma schize interior. Enquanto Sócrates, diziam, nunca saía de Atenas, (ele se afastou somente uma vez para participar como soldado no cerco de Potideia no início da guerra do Peloponeso em 432-429 a.c, e preferiu, no final de seu processo, a morte, em vez do exílio que lhe era proposto), o sofista, por sua vez, é um grande viajante: pensador itinerante, sem amarras, circulando de cidade em cidade para dar conferências e lições mediante remuneração. Consequentemente, pelo fato de sua ausência de ligações (nada o retém, pois ele não é daqui), o sofista parece necessariamente fora dos limites e, portanto, desprovido do sentido moral ancorado na história do lugar (limitado por suas fronteiras). Advém daí a acusação recorrente de imoralismo, mas também de relativismo. Sabendo que ele não receia ser banido da cidade - já que não faz parte dela diretamente - supõe-se que o sofista pode transgredir tudo, enunciar tudo o que quiser: tanto o verdadeiro quanto o falso, de forma indistinta. Ele não tem que se preocupar com as consequências de suas palavras sobre a ordem social e política. Em suma, o sofista atormenta e assusta (os filósofos, especialmente, que receiam a assimilação), de fato, esta liberdade da palavra que sua condição de viajante lhe confere.

Uma espécie de "desenraizado da cultura", ele parece ser "o homem de lugar nenhum, enquanto ele é o homem de todo lugar" (GUSDORF, 1963, p. 230) para retomar a bela fórmula de Gusdorf. Sedutor, corruptor, manipulador de sempre, o sofista arrasta atrás de si todos aqueles que dão crédito a suas palavras. Ele é a causa de sua perda, causa evidente de sua falta de luz. Somente aqueles que "veem", na medida em que não estão cegos pelo "espírito do partidarismo", pela crítica e pela dúvida, podem reconhecer como falsas pistas os percursos opinativos do sofista. Neste sentido, o propósito do verbete "Socrático" da Encyclopédie de Diderot de d'Alembert parece-me exemplar: "O filósofo é exatamente aquele que se fixa; o sofista imprudente anda sempre e 
EID\&A - Revista Eletrônica de Estudos Integrados em Discurso e Argumentação, Ilhéus, n. 11, jan/jun.2016.

perde-se a si mesmo e aos outros: toda sua dialética resulta em incertezas" (DIDEROT \& D'ALEMBERT, 1765). Com efeito, o processo argumentativo torna indiretamente manifesto o fato de que o mundo não é transparente: não é tão transparente como poderíamos pensá-lo ou como queríamos crê-lo. É por este motivo que tal processo constitui efetivamente um risco de ver o sentido se desagregar e de se obscurecer. Um risco de ver a evidência sustentada de forma fracassada pela dúvida ou pela suspeita: um risco de se ver reduzir os limites e as fronteiras. Mais do que a incapacidade em reconhecer a evidência se desviando da boa fé, o fato de argumentar sua recusa detalhando sua crítica para justificá-la e legitimá-la - como convidam os sofistas - constitui um percurso de natureza que perturba a quietude do mundo fechado. Um mundo no interior do qual um único indício vale uma prova.

Pelo contrário, a argumentação que se desenvolve traz consigo uma confrontação potente, pois envolve o adversário no combate, evidenciando posicionamentos a favor e ao mesmo tempo contra suas próprias crenças: contra aquilo que ele julgava evidente para todos e que, manifestamente, não o é. A verdade teme o exame com o "que se parece com ela", pois receia uma comparação que a tornaria precária. $O$ trabalho de precarização da relação com o mundo - que se faz sentir nos questionamentos e nos pedidos de justificação - perturba a continuidade do sentido eliminando-lhe seu caráter sagrado (separado de seu produtor humano, nada mais que humano). Ele faz do sentido o lugar de um investimento pessoal que, por definição, torna-o susceptível de aperfeiçoamento. De qualquer modo, em uma sociedade ou num pensamento fechado, o exercício da argumentação que, necessariamente, desestabiliza o sentido, é, de imediato, percebido como uma ameaça. Ela confirma, além disso, a vontade deliberada do sofista, este espírito secular, de introduzir o incerto e o jogo no interior de um sistema e de uma visão de mundo consideradas estáveis. Se uma objeção é possível, se um argumento pode ser oposto, é que a evidência, pura e simplesmente, não é. $O$ sofista, produtor de argumentos, defensor de evidências, é, por excelência, esta figura do embaralhador de pistas, de referências, de sentido. Ele conduz aqueles que o ouvem a um lugar no qual o movimento é a lei.

O abade Nadal em seu Dictionnaire d'Éloquence sacrée desenvolve, igualmente, a metáfora do viajante enganador que, precisamente, desvia do bom caminho; afasta os espíritos deste paraíso das ideias povoado por evidências e por certezas. O sofista faz perder o "fio" que, até o presente, 
EID\&A - Revista Eletrônica de Estudos Integrados em Discurso e Argumentação, Ilhéus, n. 11, jan/jun.2016.

conferia à sociedade e aos homens estabilidade e encanto. Desse modo, a viagem que este "outro, malvado" empreende em direção aos territórios desconhecidos, perigosos, não balizados, provoca o temor do pior para a segurança da interpretação. Não sabemos aquilo que vamos encontrar nestes lugares incertos: um argumento, uma crítica, uma (boa) palavra, etc. Todas estas coisas perante as quais paira, constantemente, o risco de ficar sem resposta aceitável para restaurar a evidência em sua integridade. Segundo Nadal, a enganação, iniciada com o que ele nomeia "a era das ideias" (o espírito filosófico do século XVIII), consistiu em "toma(r) a dúvida pela autoridade", a inquietude, pela luz, e a renunciar "às máximas e invariáveis da religião". A fraude, isto é, a derrota, que despertou, escreve ele: "a hora do poder das trevas", e o fim do "gosto": "O espírito racional deu a luz aos sofistas e após os sofistas, seguiram os retores e os declamadores. [...]. É então que o século começou a andar, isto é, a se afastar do grande caminho, a tomar os caminhos rejeitados (Bastou que ele se desviasse, para que nos perdêssemos com ele [...]" (NADAL, 1851, p. 454, itálicos do autor) ${ }^{10}$. Visto que se afasta do "grande caminho", já que transgrediu os limites, o sofista eterno deprime o sentido; ele o faz oscilar, o coloca em marcha e, com isso, exila os homens de sua própria pátria - moldando-os a sua imagem, inculcando-lhes seus costumes.

Levanto então a hipótese segundo a qual não seriam tanto as ideias deste outro, o sofista (aquele de Platão, Diderot, Nadal, etc.), que parecem problemáticas e inquietantes aos olhos dos defensores desta luz imutável, portanto imóvel, que é a evidência. Esta última, por sua vez, não saberia, por definição, temer a ocorrência das ideias obscuras e incertas. A ameaça imperiosa de uma corrupção dos espíritos vem de outro lugar: trata-se da viagem em si. $O$ viajante é aquele que encarna o processo argumentativo mobilizado para justificar e para defender estas ideias contra a suposta verdade. Verdade esta que ele subtrai dos olhares e da qual se distancia. Tal processo orienta aqueles que aceitam se lançar em direção ao desconhecido de seu próprio desenrolar. O perigo está aqui, no percurso claramente imprevisível que podemos ser levados a seguir colocando-nos em busca de argumentos. Trata-se de um percurso a partir do qual as interrogações, a dúvida, a incerteza das palavras e as noções podem "amadurecer e [se] desenvolver" para cobrir, afinal de contas, "toda a terra com [sua] sombra" (DE BONALD, 1833, p. 186). O percurso é a via pela qual o terror chega. Ele

10 Observaremos, aliás, que os termos empregados por Nadal são muito próximos daqueles da Encyclopédie citados acima, apesar de as ideias defendidas irem no sentido inverso. 
EID\&A - Revista Eletrônica de Estudos Integrados em Discurso e Argumentação, Ilhéus, n. 11, jan/jun.2016.

contém em si um ciclo de questionamentos, de justificações, de oposições potencialmente sem fim. Ele permite a incerteza que as antigas "luzes" poderiam reconhecer sem problemas.

Fazer seu o trajeto do sofista, apropriar-se dele, é arriscar terminar num lugar em que a primeira explicação poderia não mais ter seu caráter de evidência - a única capaz de imunizar contra o exercício da crítica. Abalada, denunciada pela evidência negada, a antiga ordem do mundo teria, desse momento em diante, que pensar sobre os novos fundamentos, repensar sobre nossas certezas.

Concretamente, mudando de lugar, posicionando-se do outro lado da colina, escalando ou descendo, a percepção do mundo evolui. O mundo é sempre o mesmo (nada de relativismo no meu ponto de vista), mas a visão que temos e a interpretação que damos ao mundo não saberiam conservar sua identidade em função do ponto de vista. $O$ trabalho argumentativo, que impõe uma viagem fora dos limites (fora dos limites da evidência, da necessidade e das verdades eternas), viagem esta necessariamente transgressiva, que constitui sempre a apresentação de um ponto de vista do qual a evidência não faz parte.

\section{Conclusão}

Com o objetivo de refletir sobre a metáfora espacial inscrita no coração da temática do volume, de destacar a sua riqueza, pareceu-me fecundo considerar e reabilitar - contra nossos preconceitos culturais - a figura do sofista: ele que se "recusa a deixar-se circunscrever pelos limites caprichosos do horizonte mais próximo" (GUSDORF, 1963, p. 230). Sua recusa constitui, afinal de contas, um convite para abrir o mundo e para abraçar a indeterminação dos futuros; um convite para se colocar sempre em perigo e para arriscar a liberdade de pensar por si mesmo, graças ao apoio do verbo eficaz. Sobre a terra plana da evidência, não haveria necessidade de nenhuma outra viagem: a verdade, dada de uma vez por todas, já é um resultado, um fim, um limite último além da morte ou a perda que nos espera. Assim, não há nada a esperar além da adesão necessária que esta verdade restringe, a não ser uma insidiosa dissolução de sua "clareza" numa esfera da incerteza e da opinião. 
EID\&A - Revista Eletrônica de Estudos Integrados em Discurso e Argumentação, Ilhéus, n. 11, jan/jun.2016.

\section{Referências:}

BENREKASSA, Georges. Lumières et sophistique. In: MASSEAU, Didier (Dir.). Les marges des Lumières françaises (1750-1789). Genève: Droz, 2004. p.19-44.

CASSIN, Barbara (Dir.). Le plaisir de parler. Études de sophistique comparée. Paris: Minuit: 1986a.

CASSIN, Barbara. Positions de la sophistique. Paris: Vrin, 1986b.

CASSIN, Barbara. L'effet sophistique. Paris: Gallimard, 1995.

CHARTIER, Jean-Pierre. Les transgressions adolescentes. Paris: Dunod, 2010.

COULOUBARITSIS. De l'iségorie à l'isopraxie. In: ACKERMANS, Hélène (Ed.). Variations sur l'éthique. Hommage à Jacques Dabin. Bruxelas: Publications des Facultés Universitaires Saint-Louis, 1994. p. 125-146.

DANBLON, Emmanuelle. Argumenter en démocratie. Bruxelles: Labor, 2004.

DE BONALD, Louis-Gabriel-Ambroise. Les vrais principes opposés aux erreurs du XIX siécle, ou notions positives sur les points fondamentaux de la philosophie, de la politique et de la religion. Avignon: F. Séguin Ainé, 1833.

DIDEROT, Didier; D'ALEMBERT, Jean Le Rond. Encyclopédie, ou Dictionnaire raisonné des Sciences, des Arts et des Métiers, par une société de gens de Lettres. Neufchastel: Samuel Faulche et $\mathrm{C}^{\mathrm{ie}}, 1765$.

DUPRÉEL, Eugène. Les Sophistes. Protagoras, Gorgias, Prodicus, Hippias. Neuchâtel; Paris: Éd. de Griffon; PUF, 1948.

GOYET, Francis. Les audaces de la prudence. Littérature et politique aux XVI et XVII siècles. Paris: Garnier, 2009.

GUSDORF, Georges. Les origines des sciences humaines (Antiquité, Moyen Âge, Renaissance. Paris: Payot, 1967.

GUSDORF, Georges. Pourquoi des professeurs? Pour une pédagogie de la pédagogie. Paris: Payot, 1963.

GUTHRIE, William Keith Chambers. Les sophistes. Trad. J.-P. Cottereau. Paris: Payot, 1976 [1969-1971].

HASTINGS, Michel, NICOLAS, Loïc; PASSARD, Cédric (Org.). Paradoxes de la transgression. Paris: CNRS Éditions, 2012.

JAEGER, Werner Paideia. La formation de l'homme grec. Trad. de André Devyver e Simonne Devyver. Paris: Gallimard, 2007 [1933-1947]. 
EID\&A - Revista Eletrônica de Estudos Integrados em Discurso e Argumentação, Ilhéus, n. 11, jan/jun.2016.

JENKS, Chris. Transgression Londres; New York: Routledge: 2003.

KANT, Immanuel. Réponse à la question: Qu'est-ce que les Lumiéres? [1784]. Trad. H. Wismann. In: Guvres philosophiques, vol. II. F. Alquié : Paris, 1985. p. 209-217.

MAFFESOLI, Michel; BRUSTON, André (Dir.). Violence et transgression. Paris: Anthropos, 1979.

MARROU, Henri-Irénée. Histoire de l'éducation dans l'Antiquité. Paris: Seuil, 1965 [1948].

NADAL, Joseph-Cyprien. Dictionnaire d'Éloquence sacrée. In: MIGNE, Jacques-Paul. Nouvelle Encyclopédie Théologique. Paris: Ed.Migne - Aux Ateliers catholiques du Petit-Montrouge, 1851.

PLATON. La République. Trad. Robert Baccou. Paris: Librairie Garnier Frères, 1950.

PLATON. Protagoras, Euthydème, Gorgias, Ménexène, Menon, Cratyle. Trad. Émile Chambry. Paris: GF-Flammarion, 2002 [1967].

POPPER, Karl Raymond. La société ouverte et ses ennemis. Trad. J. Bernard e Ph. Monod. Paris: Seuil, 1979 [1945].

VERNANT, Jean-Pierre. Mythe et pensée chez les Grecs. Études de psychologie historique. Paris: La Découverte, 1996 [1965].

Tradução:

Emília Mendes

Docente da Universidade Federal de Minas Gerais

Giselle Luz

Mestranda em Linguística pela Universidade Federal de Minas Gerais

Forma de citação sugerida:

NICOLAS, Loïc. A invenção da retórica ou a transgressão dos limites do mundo fechado. Trad. Emília Mendes; Giselle Luz. EID\&A - Revista Eletrônica de Estudos Integrados em Discurso e Argumentação, Ilhéus, n. 11, p. 159-175, jan/jun.2016.

Recebido em: 27/01/2015

Aprovado em: 03/03/2015 